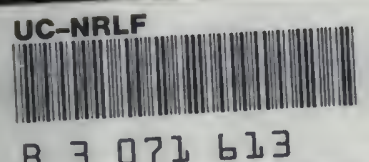

B 3 07」 bl 3 


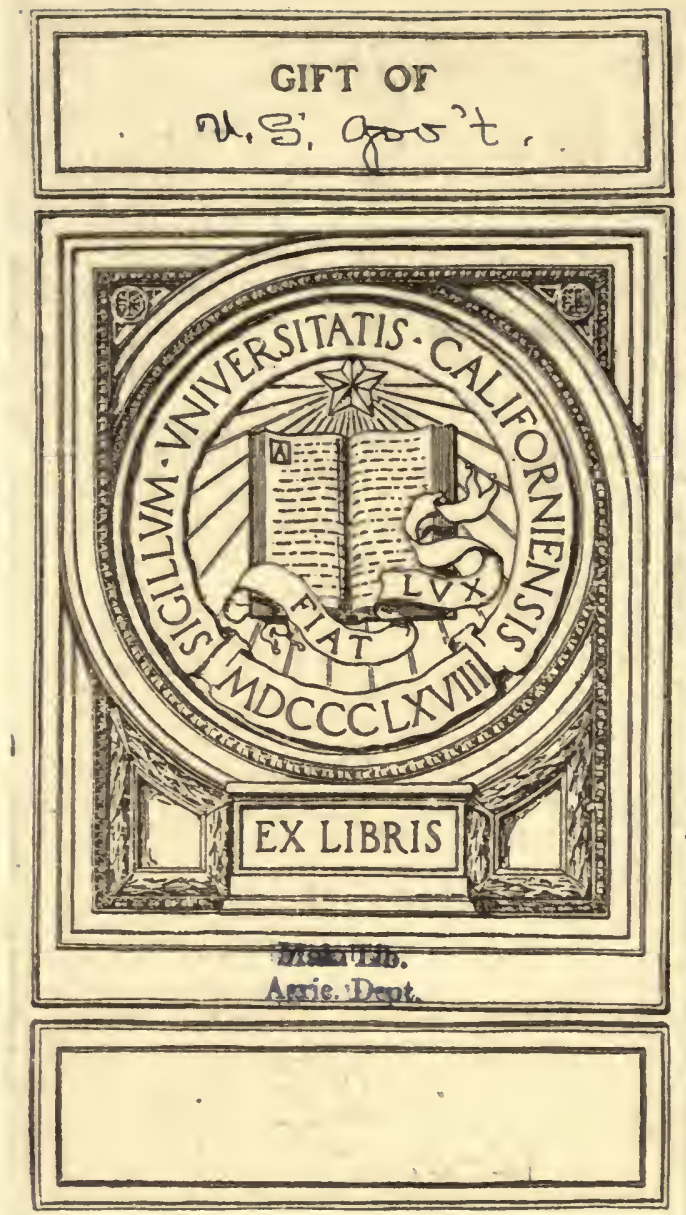




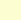




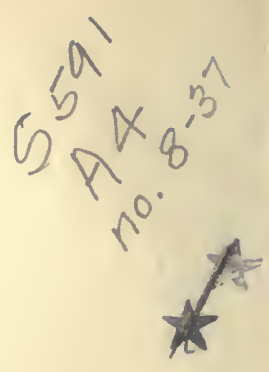

Maia ISs.

Agric. Dept. 


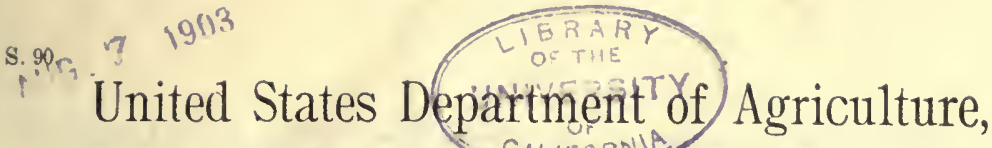 \\ BUREAU OF SOIÉ' - CORCULCAR NO. 10.}

Muton Whitay, Chief of Bureau.

\section{THE USE OF ALKALINE AND SALINE WITERS FOR IRRIGATION.}

During the summer of 1902 a representative of the Bureau of Soils visited the oases of the Oued Rihr country in the Desert of Sahara in Eastern Algeria. In these oases artesian waters carrying very large quantities of soluble matter are used successfully for irrigation. From the information gathered there, and from experience in this country, it seems that the amount of soluble matter allowable in an irrigation water has been greatly underestimated by American writers, and that many sources of water which have been condemned can be used with safety and success, provided the proper precautions are taken to prevent the accumulation of the salts. As the precautions are those which should be taken by every irrigator, even if pure water is used, it seems an important matter to bring before the American people the methods in use in the Sahara.

The staple crop grown by the Arabs in the oasis country is the date, the fruit of a palm tree known to be one of the plants most resistant to alkaline or saline conditions of the soil, but in addition to this considerable quantities of the deciduous fruits, garden vegetables, and alfalfa are produced for home consumption.

Some of the vegetables successfully grown are those considered sensitive to alkali, and yet they were being irrigated with water containing in some instances as much as 800 parts of soluble salts to 100,000 parts of water, sometimes as high as 50 per cent of the salts being sodium chloride.

The limit of concentration for irrigation water in the United States, even where only the most resistant field crops are to be grown, has been placed by some authorities at 30 parts sodium chloride (common salt) or sodium carbonate (black alkali), and at from 170 to 300 parts of the less harmful salts, per 100,000 of water. The Bureau of Soils, however, several years ago insisted that water of a somewhat higher salt content might be used if the soil had good natural drainage, or artificial drainage were supplied, and the methods of irrigation were modified to suit the different conditions. Thus in $1899^{1}$ the following statements were made after a study of soils and alkali conditions in the Pecos Valley, New Mexico:

Next to the ownership of the land and the labor questions, the most important cause of the trouble in the larger portion of the Pecos Valley is the high salt content of the irrigation water, especially in certain seasons.

At Roswell the principal water supply contains about 76 parts of soluble matter in 100,000 parts of water. At Hagerman this is increased to about 200 parts ; at Carlsbad, to 240 parts; at Florence, to 280 parts; Red Bluff, 316 parts; at Pecos City, Tex., to 400 parts; and below Pecos City to over 500 parts. Five

${ }^{1}$ Rept. 64, Field Operatious, Division of Soils, 1899. 
hundred parts of soluble matter may be taken as the extreme limit of endurance for plants, while 250 or 300 parts mark the danger point at which the results of the use of the water are very uncertain.

The limit of endurance for most cultivated plants in a water solution is about 1 per cent or 1,000 parts of the readily soluble salts in 100,000 parts of water, but it must be remembered that in field culture the water is applied to soils already containing more or less of these salts, and also that evaporation and consequent concentration immediately set in after the application of water. It was found at Carlsbad that about $300^{\circ}$ parts of soluble matter per 100,000 parts of water marked the extreme limit of $\operatorname{safety}_{*}$ of the use of water at that place.

One thing should be said in connection with the Carlsbad area, which seems rather anomalous in view of the statements of other investigators, namely, that with a water supply so near the limit of crop endurance as this becomes at times and in those areas in which there is already a large accumulation of salts, economy in the use of irrigation water, which is generally recommended in alkali regions, is one of the worst methods which can be practiced. Where the soil contains a relatively large amount of salt and but little water containing much salt is frequently applied, the ordinary evaporation will increase the salt content of the soil to such an extent that crops can no longer survive, whereas if adequate drainage is provided, and a large amount of water is used, the excess of salt resulting from the evaporation of previous applications of water, may be removed, and the soil moisture be maintained at nearly the same concentration as the water supply.

The fact that the Arabs in Algerian oases are actually growing sensitive plants by the aid of irrigation waters containing from 400 to 800 parts of soluble salts, in some instances 50 per cent sodium chloride, shows that the Bureau has been on the conservative side in its estimates, and should encourage a more hopeful feeling among the people occupying areas where only alkali water is available for irrigation.

The prerequisite to the use of water of high salt content in irrigation is the knowledge that the methods employed are opposed to the teachings of most American writers on the subject. Those who place the low limit of safety for alkaline irrigation waters have taught that where water was badly alkaline irrigation should be sparing. They have not insisted on thorough drainage, and they have warned irrigators against too frequent irrigation. With such practices the limit of concentration which they set is probably high enough, and even then all except the most sandy soils or those with exceptionally good natural drainage would ultimately be damaged.

The methods in the oases are quite different. The Arab gardens are divided into small plots, about 20 feet square, between which run drainage ditches dug to a depth of about 3 feet. The soils being very light and sandy, this ditching at short intervals insures the most rapid and thorough drainage. Irrigation is by the check method, and application is made at least once a week, though often two wettings a week are deemed necessary. A large quantity of water is used at each irrigation. Thus a continuous movement of the water downward is maintained, there is little opportunity for the soil water to become more concentrated than the water as applied, and the interval between irrigations being so short but little accumulation of salt from evaporation at the surface takes place. What concentration or accumulation does occur is quickly corrected by the succeeding irrigation. 
The native gardens are situated in the date palm groves and the vegetables and fruit are grown in the partial shade cast by these trees. The natives not only have the question of very saline irrigation waters to contend with, but the soils originally are often very alkaline. In three years they reclaim land too salty to grow the minor crops, using the saline water for that purpose, following the same plan of drainage and weekly irrigation as where crops are growing. One garden situated on the side of a salt flat and originally very saline was visited. Here alfalfa was in very good condition, and fig, pomegranate, melon, tonrato, cabbage, pepper, and other plants were growing luxuriantly. The reclamation of this plot by irrigation twice a week had taken three years.

The native gardeners exercise great judgment in adapting their crops to the soil conditions. Where most alkaline the date palm alone is found; in other parts of the grove are grown the fig and pomegranate, and in other parts the vegetables less resistant to alkali. The amount of salt in the soil sufficient to injure the palm was not determined, but the French were unsuccessful in an attempt to establish a grove, the water used in irrigation being taken from a salt pond and containing, according to field determinations, 3 parts sodium carbonate, 5 parts sodium bicarbonate, and 1,036 parts sodium chloride in 100,000 parts.

The irrigation water is all drawn from artesian wells. A number of samples were sent in to the laboratory for analysis, the results of which are shown in the following table. These are fair average samples of the irrigation waters in use, and do not represent by any means the maximum of salinity. Field tests showed as high as 816 parts to 100,000 water in actual use on soils growing vegetables.

Chemical analyses of artesian vater used in irrigating gardens in Sahara Oases, Algeria .

Constituent

1ons:

Calcium (Ca)

Magnesium (Mg)

Sodium $(\mathrm{Na})$.

Potassium ( $\mathrm{K}$ )

Sulphuric acid $\left(\mathrm{SO}_{4}\right)$

Chlorine (Cl)

Bicarbonic acid $\left(\mathrm{HCO}_{3}\right)$

Conventional combinations :

Calcium sulphate $\left(\mathrm{CaSO}_{4}\right)$

Magnesium sulphate $\left(\mathrm{MgSO}_{4}\right)$

Magnesium chloride $\left(\mathrm{MgCl}_{2}\right)$.

Potassium chloride ( $\mathrm{KCl}$ )

Sodium bicarbonate $\left(\mathrm{NaHCO}_{3}\right)$

Sodium chloride ( $\mathrm{NaCl}$ )

Total solids in 100,000 parts water $\begin{array}{ccc}\text { Well at } & \text { Well at } & \text { Well atgar- } \\ \text { oasis T'a- } & \text { oasis Kudi } & \begin{array}{c}\text { den of Ben } \\ \text { den }\end{array}\end{array}$ bes-best. Asli. , Hadriah.

\begin{tabular}{r|rr} 
Percent. & Per cent. & Per cent. \\
9.92 & 4.19 & 9.86 \\
4.52 & 6.02 & 4.26 \\
14.03 & 20.48 & 14.18 \\
4.27 & 2.35 & 2.72 \\
34.38 & 29.43 & 17.59 \\
28.06 & 36.21 & 27.05 \\
5.02 & 1.32 & 24.34 \\
& & \\
33.04 & 14.23 & 24.90 \\
13.63 & 24.29 & 7.04 \\
7.23 & 4.41 & 16.72 \\
8.12 & 4.48 & 5.19 \\
6.92 & 1.81 & 33.54 \\
31.06 & 50.78 & 12.61 \\
\hline 601.50 & 408.10 & 571.90
\end{tabular}


Enough has been written to show that much more can be done with alkaline irrigation water than has hitherto been generally thought possible, and while the intensive culture of the Algerian gardeners is not suited to our Western conditions, there is believed to be no reason why their methods can not be adapted, even with an improvement in point of economy, to more extensive cropping of the soil.

The soils in the Pecos Valley are not unlike those of the oases, and the general conditions in the two places are somewhat similar, although the irrigation water, even at the lowest stage of the Pecos River, is not as alkaline as the artesian water of the desert, nor are the soils naturally as alkaline. Employing the Algerian method of frequent irrigation with generous amounts of water on land well drained by open ditches or tile drains, large areas now out of cultivation might be used to grow alfalfa, truck, and other crops.

It is believed that the information conveyed in this circular will be of great value to the people of this country residing in regions affected with alkali, and that it will result ultimately in bringing into cultivation much land that has hitherto been thought worthless because of the character of the water available for irrigation.

Thomas H. Means, In Charge of Alkali Reclamation Work.

A.pproved :

JAMES WILSON,

Secretary of Agriculture.

Washington, D. C., July 1, 1903. 



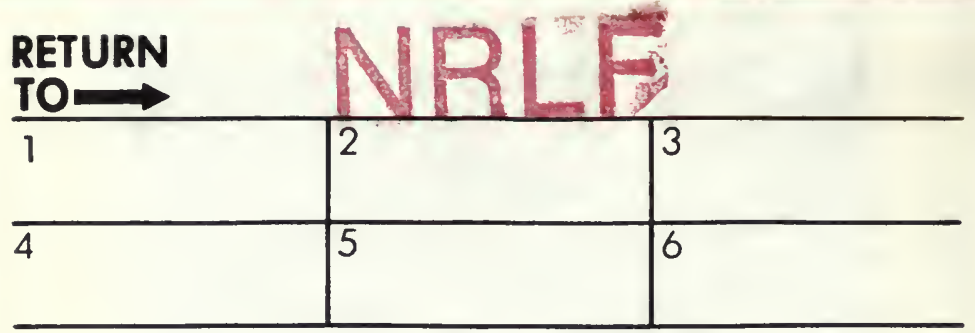

ALL BOOKS MAY BE RECALLED AFTER 7 DAYS

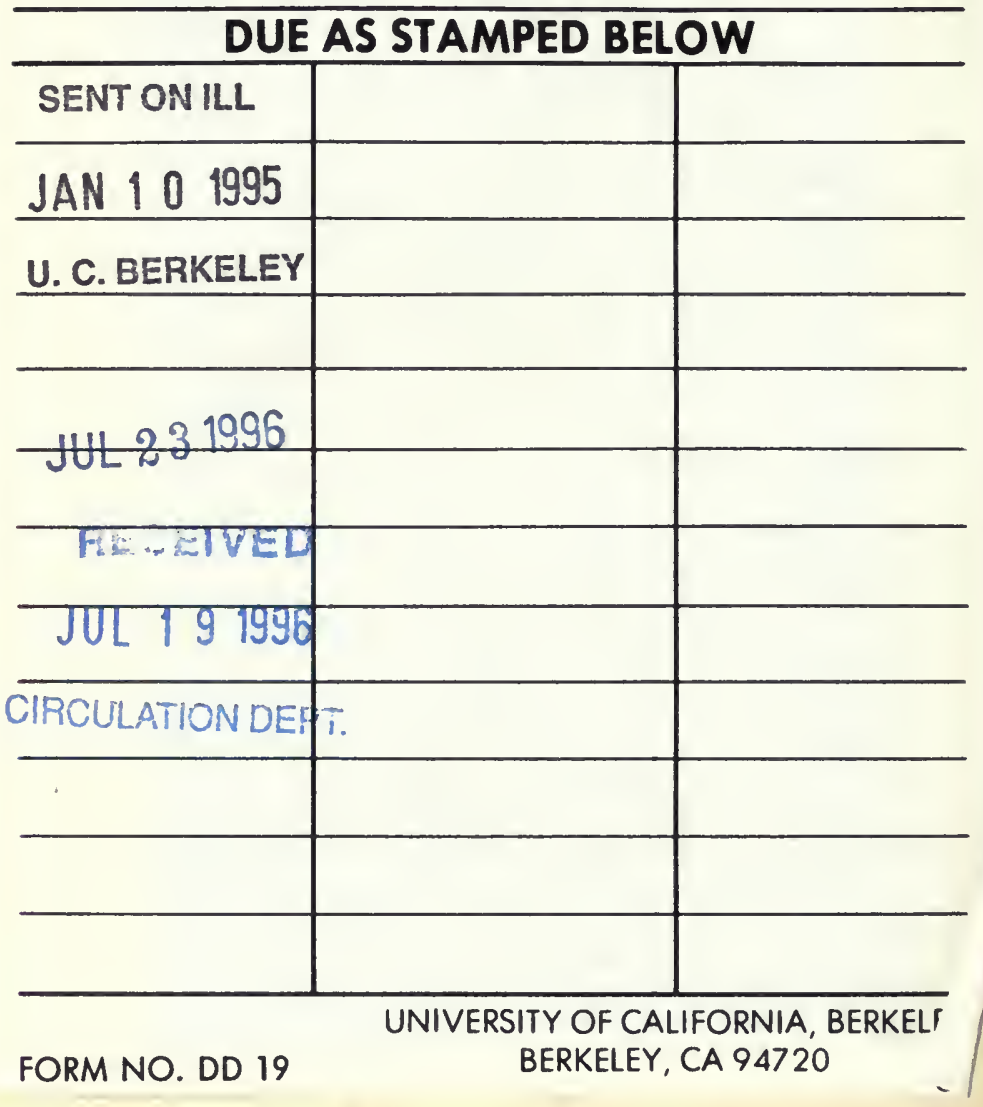




\section{YC 67891}

U. C. BERKELEY LIBRARIES

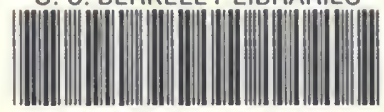

С057093926

$\%$

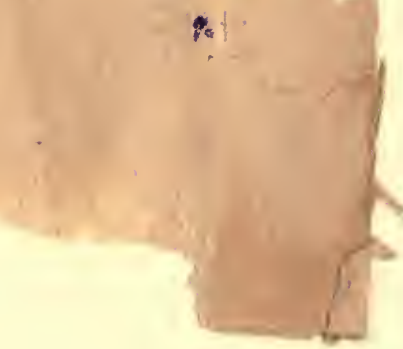

$\therefore$

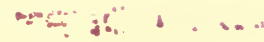

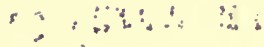




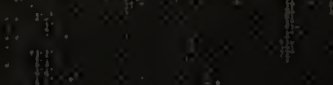
: 